\title{
- $\quad$ LICENSING, POPULAR PRACTICES AND PUBLIC SPACES: An Inquiry via the Geographies of Street Food Vending
}

\author{
REGAN $\mathrm{KOCH}$
}

\begin{abstract}
The socio-legal technology of licensing is one of the primary tools governments use to manage spaces and practices deemed risky or threatening to public order. Licensing requirements thus play a crucial role in shaping routine experiences in public space as well as the trajectories of emerging forms of public life. Yet licensing laws have largely been ignored in critical urban scholarship: too often concerned with the interpretation and critique of popular practices and public spaces, the mundane operations of urban governance are often left to practitioners and policy researchers. This article demonstrates how paying closer attention to licensure can provide valuable and unexpected insights into matters of social equality, urban amenity and economic opportunity. It does so through a comparative inquiry into practices of street food vending in New York City, Seattle, and Portland, Oregon. Drawing on ethnographic study and interviews, the article demonstrates how licensing can be involved in the production of quite peculiar and unjust geographies of practice, but also how shifts in popular culture can force a reconsideration of taken-forgranted laws. In conclusion, it is argued that a focus on licensing offers a productive pathway for new forms of critical urban research and provides a potential point of leverage in efforts to configure better and more democratic forms of urban public life.
\end{abstract}

\section{Introduction}

For several years running street food has been hailed as one of America's hottest culinary trends (Gottlieb, 2009; Shouse, 2011; Davidson, 2013). Once confined largely to produce and processed foods, offerings now range from curries to cupcakes, lobster rolls to Korean BBQ and tacos of every imaginable ethnic hybrid. The sale of food in public spaces has a long, conflicted history in US cities but recent enthusiasm has challenged the marginalization that defined the practice in the twentieth century ( $c f$. Bluestone, 1991; Baldwin, 1999; Loukaitou-Sideris and Ehrenfeucht, 2009). Aspiring chefs and established restaurateurs are pioneering new business models, launching new markets and seeking out new spaces in the city in which to vend. Many have brought substantial economic and cultural capital to the industry and are unsettling the formal rules and informal conventions that have long governed the trade. Urban governments have struggled to keep pace, often finding themselves under pressure to both nurture and restrict the trend (Zukin, 2009; Hernandez-Lopez, 2010; Valverde, 2012; Vallianatos, 2014). For while food vending might be an economically marginal practice it often carries tremendous symbolic and political weight.

Commentary on these developments has been widespread, generally taking one of two paths. Many have sought to explain why street food became trendy. Answers give reference to consumer demand for novelty and convenience, new mobile and social media technologies, and the appeal of a low barrier-to-entry business model in the post-2007 economy (Handley, 2009; Zukin, 2009; Johnston and Bauman, 2010; Rodgers

\footnotetext{
This article is based on doctoral research funded by the UK Economic and Social Research Council. My sincere thanks go to Alan Latham and Russell Hitchings for their mentorship and support. Ash Amin, Andrew Harris, James Kneale and Tauri Tuvikene all provided useful and incisive comments on earlier versions of this article, as did three anonymous IJURR reviewers. I want to thank them and all others, including the many vendors, who gave up time to help me with this project. Any mistakes herein are all my own.
} 
and Roy, 2010; Minzter, 2011). Others have focused on interpreting what the trend means for US cities and what it reflects in terms of urban socio-economic processes. Affirmative readings see it as part of a revolution in do-it-yourself urbanism that valorizes smallscale developments, pedestrian lifestyles and locally owned businesses (Rodgers and Roy, 2010; Edge, 2012). Vendors, meanwhile, are positioned as exemplifying insurgent forms of citizenship in the struggle for urban public space (Pilcher, 2008; Crawford, 1999; Devlin, 2011). Alternate interpretations have been more circumspect. Some see the rise of vending as sign of the messy informality of the global South flowing into cities of the North (Stoller, 2002), while the uncertainties vendors face indicate 'novel, extra-legal technique[s]' of public space management 'embedded in and necessitated by' the 'contemporary neoliberal entrepreneurial state' (Devlin, 2011: 61). 'New wave' vendors, conversely, are said to represent gentrification within the industry and the middle-class appropriation of a traditional source of immigrant income (Zukin, 2009; Dunn, 2014a).

The impulse towards questions of 'why' and 'what it all means' is how matters of public space and new forms of public life are most often addressed in urban scholarship. Examinations usually aim to connect new developments to wider processes, expose deeper meanings and evidence concerns about the state of contemporary urbanization (Koch and Latham, 2013). Conclusions drawn typically 'oscillate between optimism and pessimism' (Barnett, 2014: 884) while mundane questions of practice and consequencewhat these changes do and how they are done-are often ignored, left to practitioners or the inquires of policy researchers (Valverde, 2003). This is a significant oversight given that attending to such details can yield surprising and important findings about the object under investigation. It also relates to a limited view of what counts as 'the politics of public space' (Low and Smith, 2006) in much avowedly critical urban scholarship. Content with denouncing particular developments or celebrating acts of resistance and transgression, inquiries frequently fall short of providing information that might be used in efforts to reconfigure spaces of public life to better meet the diverse needs of their inhabitants.

This article takes as its starting point the need for urban scholarship to become better attuned at registering and evaluating how different forms of public life are assembled (Amin, 2008; Farías, 2009; 2011; Koch and Latham, 2012). Following Sayer (2011) it locates the transformative potential of social science inquiry less in generalized critique and more in contributing to practical discussions about the possibility, feasibility and desirability of different forms of social organization. The contribution offered here is an examination of a primary technique governments use to manage a broad range of popular practices and public spaces: the socio-legal technology of licensing. A focus on licensure is vital to the study of street food because it provides a direct means of interrogating the legal requirements that shape how, when and where vendors go about their trade. Examining licensing regimes helps to make sense of why some places have a thriving street food culture while in others the practice is scarce, or exists only on an informal basis-sometimes even despite official efforts to bring about reform. As this article will demonstrate, licensing folds into the production of some very distinct and often quite durable geographies of public life: some marked by inclusiveness and shared opportunity, others by inequality and conflict.

Of course, licensing's reach extends far beyond the issue of street food. Licenses are required for all sorts of activities deemed threatening to public order in some way: those that take place on public property, that involve private property open to the public or involve objects deemed potentially harmful. Sociolegal scholar Mariana Valverde $(2003 ; 2011)$ has argued that licenses have become ubiquitous to how contemporary societies are governed because they effectively reconcile popular demand for problematic activities with state concerns for public order and safety. They enable authorities to regulate activities and spaces by setting specific conditions of conduct without having 
to ban or intensely supervise them. Instead, management is contracted out to private individuals: not to private security forces but to those who make their living from such activities (Valverde, 2003). In the contemporary US nearly $30 \%$ of the workforce is required to obtain a licence of some form in order to legally work for pay (Kleiner and Krueger, 2010).

Licensing arrangements thus play a crucial role in shaping routine experiences in public space and the trajectories of emerging forms of public life. They prefigure how aspiring entrepreneurs are enabled or constrained in their pursuits, and provide a tool through which municipalities can address, and in many ways, depoliticize difficult issues. Given that licenses often serve as a dividing line between deviance and legality (Skolnick and Dombrink, 1978) they are also implicated in questions of the state's power to produce informality in criminalizing or legitimizing certain activities and modes of practice (Roy, 2005; Mukhija and Loukaitou-Sideris, 2014). Along with municipal tools such as zoning and land-use restrictions that have garnered academic scrutiny, licenses are part of a largely unpublicized infrastructure that profoundly shapes how cities are organized (see Valverde, 2003; 2009a; Blomley, 2010). Yet perhaps considered too banal or ubiquitous to warrant serious attention, urban scholars have largely ignored systems of licensure and their differential effects. ${ }^{1}$ This is a crucial oversight not only because of licensing's reach. An examination of licensure demonstrates how socio-legal configurations can interact with popular practices in rather surprising and unintended ways. Discerning what opportunities are being gained or lost, or who benefits, from a given set of arrangements requires much more than a simple comparison of laws on the books.

Research for this article is based on 20 weeks of participant observation in New York City, Seattle and Portland, Oregon. This includes time spent shadowing vendors going about their daily routines, conducting ride-alongs with health inspectors, attending administrative hearings for licensing infractions, and working as a volunteer in the office of the Street Vendor Project-a vendor advocacy group in New York. In addition, 29 formal interviews were conducted with vendors, health inspectors, regulators, police, legal advocates and other persons relevant to street food in these three cities.

The article proceeds by profiling four different vendors as a way of anchoring the substantive sections that follow. The next section examines the rationale for licensing and considers what it enables for municipal governments and what it demands of vendors. The following sections then move from New York to Portland and then Seattle to examine the effects of licensing upon practitioners and the culture of street food in these cities. Findings demonstrate a range of unintended policy outcomes and unjust effects, but they also show how shifts in popular practice-collective understandings about what is permissible and viable-can expose undesirable conditions and bring pressure for regulatory reform. In conclusion, it is argued that licensing, as a critical component in the governance of people and things, provides a range of unexplored possibilities for urban research. However, leveraging the potential of urban research to bring forward better forms of collective life demands new ways of thinking and working as critical scholars.

\section{Four vendors, three cities}

Aziz is a hot dog vendor in New York City. ${ }^{2}$ Originally from Egypt, he got into vending 13 years ago through an extended family member who owns a commissary and manages a fleet of carts. ${ }^{3}$ For years Aziz 'hustled', moving spots four or five times daily in response to rhythms of foot traffic and when told to by the police. For the past

1 Mariana Valverde's writings are a key exception and have provided significant inspiration for this chapter (Valverde, 2003; 2011; 2012; see also Hubbard et al., 2009; Blomley, 2010; Coulmont and Hubbard, 2010).

Aziz is a pseudonym. All other names in the article are actual persons.

A commissary is a licensed premise where commercial food is prepared. They often provide additional services, including cart storage and cleaning, product purchasing and serve as informal facilitators of practical knowledge about vending. 
five years, however, he has worked primarily from two sidewalk locations: one near Times Square during weekdays, the other near Grand Central station on evenings and weekends. The nondescript cart he owns looks like a thousand others in the city, selling hotdogs, pretzels and cold drinks for $\$ 1-2 .{ }^{4}$

Kim Ima is the owner and operator of Treats Truck in New York City. She sells handmade cookies, brownies and other desserts from a retrofitted postal van she calls Sugar. A native New Yorker, Kim launched her business in 2008 with the help of a non-profit business startup. The same year she won 'Best Dessert Vendor' at the NYC Vendy Awards and developed a loyal following. Each day her truck starts at a commissary in Red Hook, Brooklyn where it is loaded up with freshly baked goods that are sold at routine locations in Midtown and Lower Manhattan-usually metered parking spaces from which Kim sells to customers queuing on the sidewalk. Loyal fans are informed of her whereabouts on Facebook, Twitter and through a phone number listed on her website.

Nong Poonsukwattana emigrated from Bangkok to Portland at the age of 23, having just $\$ 70$ to her name. After working for years in various Thai restaurants, she saved enough to buy a used trailer and kitchen equipment and decided to launch her own business. Khao Man Gai-chicken and rice-is a dish commonly found in street markets of Asia, and at Nong's stall it is the only item on offer. She vends from a downtown parking lot in a privately owned space that she leases from a property management company. Alongside her, more than 30 other vendors share the same lot-forming what is known in Portland as a food cart 'pod'.

Seattle's Marination Mobile is one of the most celebrated food trucks in the US. It was awarded the title 'Best Street Food in America'on Good Morning America, has been featured on The Travel Channel and Food Network, and has had write ups in a wide range of international magazines including GQ, Gourmet and Dwell. The truck is a joint endeavour of Roz Edison and Kamala Saxton who, with three masters degrees and decades of management experience between them, brought an extraordinarily high level of precision and project management to a street food operation. Their truck, which they call Big Blue, was custom built in Los Angeles and was up and running 21/2 months after the idea was conceived.

The circumstances that define these four operations differ greatly, yet they also share several commonalities. Through these we can develop a comparative form of 'narrative inquiry' (Flyvbjerg, 2006) into the demands vendors face in different cities. For example, each of the four had to follow a similar number of steps to get up and running: putting together a business strategy and menu; finding a vehicle and equipment; navigating the rules of public health, business and taxation, fire and safety and public right of way; finding spaces to vend and staying clear of conflict in order to keep them. They have all been successful in what they do-finding their original reasons for vending more or less fulfilled and surviving as small businesses owners for over five years. This is no small feat in the notoriously difficult food industry in which failure affects roughly a third of new restaurants in the first year and two-thirds by the third year (Parsa et al., 2005).

\section{The rationalities and demands of licensing}

To begin our examination of licensing and its effects, let us start with Aziz. He arrived in the US speaking limited English and was pressed to find a way to support his family. Some in this position vend completely informally-and therefore illegally-but the risk of being arrested and having one's goods confiscated is high. Getting a license, however, is a fairly straightforward process in New York. Aziz was required to register 
his personal details with several different state and municipal departments, attend an eight-hour food safety and hygiene course, and pass a practical exam. He then submitted a photograph and a $\$ 50$ application to the city's Department of Health and Mental Hygiene (DOHMH) and waited roughly three weeks. The licence was issued in the form of an ID badge that must be worn at all times while vending.

Bureaucratic requirements such as these enable authorities to readily identify and monitor Aziz, subjecting him to both scheduled and surprise inspections. They also facilitate the issuance of fines for any violation of health, sanitation or fire code. In New York, unlike Seattle and Portland, these can be given by departmental officials and police officers-should, say, Aziz fail to wear gloves or have a piece of equipment touching the ground. On-the-spot citations can also be issued for other violations of city rules and laws-everything from vending too close to a bus stop or failing to display prices-and the arrangement ensures that an accumulation of unpaid fines impacts a vendor's longterm ability to practice. Failure to pay or have them successfully contested results in an escalation of fines and eventually the revocation or non-renewal of the license.

In a range of ways, the rationale for this process aligns with Valverde's (2003: 236) description of what licensing does generally:

The legal technology of the license allows governments to ensure that certain spaces, activities and people are under constant surveillance and are subject to immediate disciplinary measures, but without state officials or centralized state knowledges being involved in this micro-management.

However, the terms surveillance and discipline should be qualified. For while Valverde's work is quite nuanced, there is a tendency in critical scholarship to throw around such words somewhat hyperbolically in critiques of government power. Academic versions of state phobia can make it difficult to imagine policing and regulation as ever being pursued for legitimately public purposes. Yet those familiar with street vending know that mobile carts and trucks can generate a whole range of public disorders. Rightly or not, vendors are often seen as unfair competition for brick-and-mortar businesses and as privatizing public space at the expense of other potential uses. Conflicting demands are intensified when streets and sidewalks become congested, or when there are noisy generators, unpleasant fumes and litter. There are also health risks particular to street food, such as the difficulty of maintaining safe temperatures for cooking and storing food, and the potential for germs to spread given how frequently vendors' hands move between food, equipment, customers' hands and money. Illnesses from carts are rarely reported given their mobility and because some carts, such as Aziz's, do not have names that can be easily recalled. The idea of an integrated, central agency to comprehensively manage street vending might seem a reasonable solution to such problems, but the multiple departments and competing interests involved have historically made such agencies difficult to establish (see Devlin, 2010; Valverde, 2012; see also Morrow, 2009). ${ }^{5}$

A fundamental feature of licensing is that it delegates responsibility for managing risks to the license holder, enabling governments to distribute and extend power in a range of ways. Regulations can stipulate conditions required to obtain a license, and mandate practical obligations that must be fulfilled in order to keep it. The threat of fines and licence revocation provides a constant point of accountability, giving even sporadic law enforcement significant leverage in shaping conduct. But we can also consider how responsibility is taken up in the form of 'self-surveillance' (Vaz and Bruno, 2003)

5 Multi-departmental taskforces assembled to curtail vending have been more common, as was demonstrated in Seattle in the 1980s and in New York in the 1990s. 
as practitioners develop the capacity to protect customers and themselves from certain harms. Application procedures and training sessions can help vendors develop practical know how and material conditions necessary for minimizing risk. As Kamala in Seattle related:

Before I started this [vending], I'd never really cooked for anyone but friends. So I've become an expert on food safety. I can tell you all the required temperatures, sanitary procedures, food storage criteria, the optimal size of water tanks and wastewater disposal, you name it. It's a lot to learn at first, sure, but none of it really is time wasted. It's just how you learn to get on with doing things. The last thing we'd want is to make someone sick-much less an entire line of people (4 May 2011).

A license can also serve as a form of public validation-a sign that one is legitimately conducting their businesses. Tellingly, in 2011 when a New York legislator proposed that street food vendors should be subject to the same 'letter grades on the door' system as restaurants, the response among vendors was overwhelmingly one of agreement (AMNY, 2011).

The effectiveness of various training and inspection regimes is an empirical question, but labour market research suggests that those whose professions require a license are more likely to perceive themselves as competent practitioners than those who do not (Kliener and Kruger, 2010). Vendor organizations in New York have helped to empower their members by helping them obtain licensure and by teaching them how to assert themselves in conflicts on the basis of their rights as licenced, law-abiding and regularly inspected professionals. Those able to secure regular vending locations often become important 'public characters' (Jacobs, 1961; Dunier, 1999) and are first to alert authorities to problems and to the presence of unlicensed vendors. ${ }^{6}$

A second notable aspect of licensing is that it facilitates coordination between governmental departments. Application processes and inspection routines can require license holders to demonstrate that criteria set by other jurisdictions have been met. Enforcement officials can often deal with emerging problems simply by communicating with officials in other domains and aligning their inspection criteria. For example, one dirty secret of the street food industry is that wastewater and cooking oil are sometimes directly released into storm drains, creating environmental health problems that have only come to light due to the increased number of vendors in recent years. Portland's planning department has dealt with this by requiring vendors to submit proof of contract with a licensed disposal service. In Seattle, where the daily use of a commissary is required, the health department now includes wastewater and oil disposal facilities as part of their commissary requirements. Enforcement practices can also be streamlined or experimented with to provide more thorough inspection routines. Following an explosion at a food cart in Portland, the fire and health departments coordinated in this way to minimize the risks associated with the use of gas canisters without banning them on mobile vehicles as many cities have done.

A final key feature of licensing is that it provides local governments with flexibility to allow or curtail problematic activities on a situational basis. Regulations do not have to be enforced to the letter of the law, particularly in cases when the issue is non-contentious. If conflicts do arise, authorities can step up enforcement or move activities to less problematic locations. While such arrangements tend to privilege those capable of negotiating compromises, they also help to disperse and depoliticize conflicts without the need for formal legislative processes (which have historically tended to

6 The role of vendors as 'eyes and ears on the street' was dramatically highlighted in the summer of 2010 when licensed vendors were first to alert police to an attempted car bomb attack in Times Square. 
result in further restrictions against vendors). This helps to explain why, in cities with large vending populations, rules are typically applied with a tremendous amount of discretion, particularly between neighbourhoods such as New York's outer boroughs where informal vending is common (Dunn, 2014a; 2014b), and why few politicians have found it politically worthwhile to try and comprehensively reform vending laws (Devlin, 2010).

\section{- $\quad$ Licensing's rationale vs. reality}

The analysis thus far indicates why licensing should not be instinctively viewed as an undesirable form of social control. Requiring practitioners to demonstrate basic competencies and satisfy certain conditions might be more adequately characterized as a form of 'caring surveillance' (Wood, 2003: 236): a type of policing easily overlooked by urban scholars attuned to registering encroachments upon public life. Optimally configured, licensing can enhance the ability of people to monitor their own actions, protect the public from harm and enable municipalities to manage troublesome practitioners. Demand for popular activities and the entrepreneurial pursuit of profit are thus reconciled with state concerns for public safety and order. The governance effect is a particularly liberal form of biopolitical spatial ordering that reduces the need for more intrusive surveillance and discipline by the state.

And yet, licensing's effects often exceed their rationale and lead to a range of unintended consequences. Conditions of licensure sometimes have little to do with maximizing collective wellbeing but rather are reactionary and site-specific responses to complaints or the wishes of privileged interests. Licenses can be pragmatic problemsolving tools but they can also stifle opportunity and innovation, forming what Holston (2008: 33) describes as 'entrenched regimes of legalized inequality'. To illustrate some of these effects, the article now turns to the four vending operations profiled to examine how licensing laws bear down upon the actual practices and cultures of street food vending in their respective cities.

\section{The licensed ambiguities of vending in New York}

New York City is home to more than 19,000 licensed street food vendors (Dunn, 2014b). They are an embedded part of local public life and symbolic figures in the city's mythology of being the epicentre of bootstrap capitalism. The right to vend in public space is enshrined in both state and municipal law, yet the current vending landscape is defined by a tremendous number of problems. As this section will highlight, many of them can be directly tied to licensing arrangements and the ambiguities they generate.

\section{- $\quad$ Difficulties and illegal detours for aspiring vendors}

For Aziz and Kim, getting a license to vend was not difficult. Getting the associated vehicle permit was an entirely different story. These are capped at 3,000 total permits - a policy dating back to 1983 when real estate and business interests exercised tremendous leverage in shaping the public realm in Manhattan (see Smith, 1996; Greenberg, 2008; Devlin, 2010).? Today, the wait for a general vehicle permit is so long that the DOHMH rarely even adds names to it lists. There is no restriction, however, on licensed vendors working on someone else's cart. Therefore, the entry into food vending for most new licensees is as an employee or subcontractor. Given that many arrangements are informal, the work is typically composed of very long hours and low pay-often below minimum wage. New hires often have few other employment options and are lured by hopes of eventually getting a permit of their own. 
Aziz worked on another vendor's cart for several months after getting his license, but could not afford to live on such low wages while potentially waiting years for a vehicle permit. He therefore did what many new vendors do: illegally rented one. The practice is common and extremely lucrative for existing permit holders. The twoyear permit renewal fee is just $\$ 200$ but they can be sold for much more. In the 1990s and early 2000s the going rate was roughly $\$ 1,000-5,000$ but since around 2008 , when the food truck trend took off, it has become more like $\$ 9,000-10,000$ and can go up to as high as $\$ 20,000$ (Reddy, 2011). This is for the permit. The cost of the actual cart or truck is another matter. In many cases vendors acquire their own vehicle and just rent a permit. However, there are myriad arrangements organized through commissaries, family networks and third-party brokers who manage the illegal transfer of permits and vehicles.

Vendors often acquire licenses for multiple family members simply to increase the chances of getting a vehicle permit. For the past seven years, Aziz has rented his permit from the wife of a deceased Greek vendor, but he has been fortunate to acquire a summer-season temporary permit in his wife's name. He renews it annually on her behalf and then contracts it out, usually to other immigrants from Egypt. Given that a license is easy to obtain and there is no cap on numbers, it is not difficult to find others to employ. Further, penalties for violations fall upon the licensee but do not affect the vehicle permit holder. Therefore it is actually advantageous for the permit holder not to be the one out on the streets vending. If an employee gets more fines than they can pay, they forfeit their license and are replaced. ${ }^{8}$ This perpetually puts new, inexperienced vendors on the street-thus increasing the likeliness of harm and disorder-and limits opportunities for vending to provide a stable income to those who need it most.

Kim provides a rather adept summary of the current situation:

You have this informal, really sort of shadowy and shady world where getting a business up and running is not a matter of just going through formal, legal procedures. For most people, it's about asking around commissaries and depots, finding a retired Greek or whoever and pretending to be business partners at the inspection. Or it's about these guys who own commissaries and depots basically running the show-signing up their friends and relatives to own permits and then hiring immigrants to actually staff the carts for very little pay (14 July 2012).

This reality is no secret to municipal authorities. In 2009 the Department of Investigations (DOI) filed charges against six persons involved in broking illegal permit transfers and issued a report suggesting that at least 500 permits had been obtained through them (DOI, 2009). The DMHOH now requires permit owners to be present for the vehicle inspection, but this does not change the practice of renting them out. As an anonymous interviewee described it:

These old guys [permit owners] fly back from Florida or Greece and pretend that they're opening a trendy new cupcake cart or fusion taco truck and the inspectors don't bat an eyelid-all they care about is whether the cart meets standards.

The DOI report recommended that the DOHMH switch to a competitive bidding process similar to that of taxi medallions-a move that would enable the city to collect revenue and capitalize on the scarcity of the permits. The city's Parks and Recreation

8 As of April 2004, mobile food vending violations will be issued to the permit holder who will be responsible for paying fines. This policy change is likely to have substantial impacts upon practices of subcontracting and transferring permits, but at the time of writing, these are not yet clear. 
Department have adopted this entrepreneurial model of urban governance (Harvey, 1989) and generate $\$ 4.5$ million annually by auctioning off their spaces; a single pitch in Central Park recently went for $\$ 289,500$ (Roberts, 2013). However, such policies have enabled food distribution and cart-fleet companies to dominate the industry while driving down wages for those on the front line. An alternative policy for the city's streets and sidewalks would be to simply increase the number of vehicle permits allowed. This would eliminate the black market, expand opportunities for entry-level vendors and raise the quality of street food available in the city.

- $\quad$ Unhealthy and unimaginative foods

Although widely regarded as America's culinary capital, the national trend towards ethnically diverse and high-quality street food has been less prominent in New York than elsewhere (Shouse, 2011; Davidson, 2013). There are notable exceptions, of course, but the majority of the city's vendors sell products that are pre-packaged and heavily processed. Much of this stems from a confusing three-tier permit system that regulates what sort of preparations can be made on a vehicle. Roughly $60 \%$ of the city's permits are on the lowest tier, meaning that vendors cannot cook food on the vehicle. Aziz would prefer not to sell hot dogs-as a practicing Muslim, he does not even eat them-but upgrading to a higher-capacity vehicle is both costly and confusing. Likewise, Kim gave up on her dream of baking treats directly on the truck after doing the calculations and hearing tales of others who spent money on vehicle upgrades but failed to receive a higher-tier permit.

Vendors are wary of investing in a cart or truck until they can secure a legal permit, and it is difficult to get a business loan without one. Satisfying the highest permit tier requires a truck that can cost anything from $\$ 45,000$ to well over $\$ 100,000$, whereas a basic sidewalk cart like Aziz's can be purchased for as little as $\$ 3,000$. The convenience and economies of scale that commissaries provide is a further reason why vendors are often reluctant to branch out with their menus. Aziz's commissary is typical in that it offers not just cart storage and cleaning facilities but also food purchasing and restocking. All of the 45 vendors who use his commissary sell nothing but hot dogs or shish kebabs. Street vending's nature as a short order, small-ticket business means margins are generally tight and increased investment can offer limited returns. These realities are further constrained by licensing structures widely considered arduous and oppressive. The result is a street food landscape that is a poor reflection of the city's tremendous ethnic diversity and culinary talent.

Confusion, hardship and harassment

Cross-jurisdictional matters further complicate vending in New York. Federal courts shield activities falling under First Amendment protections, including the sale of goods deemed expressive of free speech, from any sort of permit cap. At present, if municipal rules allow for any form of vending in a public space then the sale of printed news or reading material, as well as canvases, photos, prints and sculptures, must also be allowed (Dunier, 1999; Devlin, 2010). New York State-level privileges also grant specific privileges for military veterans. Separate licensure categories-coded as white, yellow and blue-respectively exempt all veterans from licensing and permit caps; disabled veterans from most street closure laws; and some disabled vendors from restrictions in the coveted spaces of Midtown Manhattan. An effect of these laws is that wherever a blue-licensed vendor sets up, they effectively open up the street to First Amendment vendors, so long as a licensed veteran is present. The practice of 'rent-a-vet' is not uncommon: vendors will hire a veteran to locate on a particular corner or sidewalk to make vending legal. The veteran may become an employee or partner of the stallholder or just spend the day merely hanging out in case a police officer or inspector shows up. These regulatory complexities generate much confusion about the law and have led to 
increased pressure for all types of vending to be restricted in areas where the sale of merchandise is seen as problematic (Devlin, 2010).

Eight different municipal departments in New York have regulations related to vending, comprising several dozen pages detailing (in English only) where, when and how vending is to be practiced. New police officers are expected to know administrative rules and city codes, but ultimately the burden is placed on vendors who have to navigate the lengthy, fragmented and sometimes contradictory lists of vending rules and conditions. This pressure significantly intensified in 2006, when an executive order under Mayor Bloomberg raised vending-related penalty fares to the maximum level allowed under city bylaws. Tickets for all infractions, whether interrelated or not, became aggregated up to $\$ 1,000$ after the sixth violation. This gave police officers and anti-vending interests tremendous leverage in conflicts and negotiations, for it is safer and less hassle to comply with police or third-party requests to move from contested locations rather than risk penalties.

The severity of penalties makes vendors particularly susceptible to unfair treatment-especially those with limited English or little working knowledge of the law. Business owners, property managers and competing vendors can often intimidate vendors into moving on by pointing out a violation (real or not) and threatening to call the police. Public-private governance mechanisms, most notably business improvement districts, frequently use private security to scrutinize and sometimes intimidate vendors into moving elsewhere, and have become adept at using design and landscape interventions to render legal vending spaces unusable (Devlin, 2010; 2011). An intensive five-year campaign by vendors and their advocates succeeded in 2013 when penalty fairs returned to pre-2006 levels. Yet minor offenses can still accumulate to penalties of $\$ 500$ per infraction and it is not unusual for officers to issue three or four tickets at once-even without prior warning.

The recent growth of higher-end food trucks has further complicated the situation, altering the dynamics of vending in ways that existing policies-however flawedsimply were not designed to address. Police regularly have to interpret the law in cases when it is quite vague and vendors vary widely in their capacity to negotiate. Kim has never received a penalty violation. Her cultural capital and social skills certainly help, as does her popularity with customers, but she has also increasingly found herself 'moved along' by police for various reasons-particularly relating to the grey area of whether vending from a parking space is legal. Aziz gets three to four tickets per year, far fewer than many vendors, but he has worked from the same two spaces for several years. The tickets he does get rarely hold up at hearings because they are inaccurate or issued incorrectly. Less experienced vendors, however, are often unable to contest fines or cannot afford to pay them, eventually becoming unable to renew their licenses.

As an initial summation, New York's vending landscape demonstrates the role of licensing in facilitating and constraining social and economic opportunities. The technique is effective in mediating contentious and complex issues of public space, allowing vending to be practiced with differing degrees of formality. Yet the accumulation of regulatory conditions-historically and cross jurisdictionally-has also produced a great deal of ambiguity, inequality and injustice. Turning now to Portland, we consider the operations of licensure in a very different set of circumstances.

\section{Portland, Oregon: 'cart-opias' and social innovation}

Anyone who has visited Portland in recent years will have noticed, and likely eaten at, the hundreds of food carts around the city. Twenty years ago there were just a few dozen, but since the late 1990s the number has climbed by roughly 25 per year. The biggest rise came in 2010 as 140 new operations opened in a single year. At present, there are 603 registered with the county. This astounding growth has led to some remarkable collective benefits for the city and its residents. 
- New configurations of amenity and opportunity

In 1997, a seemingly unremarkable event helped to catalyse Portland's street food boom. Two unrelated vendors-King Burrito and Saigon-To-Go-began operating at opposite corners of the same downtown parking lot at Southwest 5th and Stark. This was the first known instance of vendors using designated car parking spaces and an early example of carts clustering in one location. There was nothing in Portland's zoning codes, bylaws or licensing conditions that stood in the way of this development, so other vendors gradually followed suit, renting spaces alongside others or in other available spaces. Rather than directly competing, clusters of carts formed microagglomeration economies that became known as a food cart pods.

There are now more than two dozen pods in the greater Portland area. Nong works in the city's largest and shares it with more than 30 others selling Polish, Korean, Bosnian, Chinese, Mexican, Japanese and other food. Like the original pod a few blocks away, Nong leases her space on a monthly basis while the centre of the lot remains open for day-rate car parking. Landowners can charge vendors between $30 \%$ and $50 \%$ more per space and some have started adding features such as seating, shelter, toilets and cash machines to command such rents. Vendors have also come to expect infrastructure support, including electricity, sewage and water hook-ups as part of the rent. Depending on the location, they often have very different configurations. Pods downtown are generally largest and cater to lunch crowds who take food back to their offices or eat at nearby parks and plazas. In the outer-urban areas, pods tend to become more elaborate. Rather than have carts line the perimeter of a block face, they tend to turn them inward and put tables and chairs at the centre, similar to a food court in a shopping mall. Some have decorative features resembling a garden centre or theme park, and many host special events including movie nights and live music. Around the city, many empty lots or foreclosed businesses also have carts with tables and chairs set out.

\section{- $\quad$ Collective benefits}

So, what exactly have the people of Portland gained through these small innovations in street food vending? A great deal according to most accounts. Many people eat at them several times a week and comparing them is a frequent topic of conversation around town. The quality and variety of food available is extraordinary. Tight competition means that prices are competitive and standards are high. The pods also provide a range of social amenities beyond food: they are important places for people to meet up, socialize and relax. Going to them presents an easy way of engaging with people in the neighbourhood and a reason to get outside and travel on foot or bike. They also draw in tourists and feature in guidebooks as some of the city's must-do attractions.

Cartopia: Portland's Food Cart Revolution (Rodgers and Roy, 2010), selfpublished by two cart-loving locals with urban planning backgrounds, provides an astute, celebratory analysis of the phenomenon. It argues that food carts and pods facilitate urban sociability in ways that restaurants often do not by allowing customers to support business owners directly and to develop regular relationships with them and other customers. They point out that food cart pods provide a highly desirable alternative to blocks of parking lots and undeveloped land, greeting passers-by with 'a colourful and aromatic street wall rather than a line of automobile bumpers' (ibid.: 267). Rodgers and Roy further suggest that the growth of food carts has altered the urban development landscape in Portland by making evident the benefits of microscale retail. This includes the value of intensively using available commercial space, often through subleasing; the benefits of having smaller retail units with lower overheads and rents; the ability to test the market and build customer loyalty; and the potential for shifting successful small-scale operations into much larger ventures. 
The economic benefits of the industry are bolstered by a study estimating that between $\$ 11$ million and $\$ 23$ million in annual revenue is generated in food cart sales, while cart owners pay between $\$ 2$ million and $\$ 5$ million in annual rent (Chastain, 2010). Carts also provide an entry point into owning one's own businesses, an opportunity notably taken up by many ethnic minorities and immigrants in Portland. In a study by postgraduates at Portland State University, over half of vendors surveyed outside of downtown were Hispanic, and over half of all vendors surveyed were born outside the US (PSU, 2009). Those surveyed conveyed that street vending was a desirable way of making a living, with the benefits of 'independence, flexibility of schedule and opportunity for family involvement' being the most cited reasons. Several cart owners in Portland have scaled up their business to include additional carts or a brick-and-mortar restaurant. In the past two years, Nong has done both: opening two more carts and a restaurant.

\section{- $\quad$ Lessons in supportive regulation}

A question commonly asked of Portland is how they did it. What role did governance or planning policy play in allowing, or perhaps generating, such a lively street food scene? Mayor Sam Adams has answered by saying that the city 'worked really hard to stay out of the way' (Mesh, 2010). Given that Portland tightly regulates many aspects of urban land use and development (especially in comparison to many US cities) the response seems accurate. The city is widely known for its stringent environmental and urban planning laws, while at the same time being relatively laissez-fare on social practices often curtailed elsewhere. Things like strip clubs, urban livestock, alcohol distilleries and naked bike rides do not attract much official interference in Portland. Relaxed bureaucratic processes and enforcement policies in the city are no secret either, as is evident throughout Portland's culinary scene and its 'artisan' economy' more generally (Heying, 2010).

What tends to be underplayed in the celebratory discourse on Portland's planning practices (e.g. Roy and Rodgers, 2010; Browne et al., 2014) is the degree of socioeconomic and ethnic homogeneity that defines the city in comparison to most places in the US. Portland has one of the smallest immigrant and ethnic minority populations among major American cities, and the downtown area has become less diverse over the past decade (Hammond, 2009; Hannah-Jones, 2011). In addition to having relatively few of the social groups historically drawn to vending when other options are less available (Hall, 2012), the demands on space in Portland are much less intense than in other cities. And yet Portland's laws are quite restrictive in terms of vending in public space. Less than ten vendors use city sidewalks and there is very little vending that takes place in parks. The sheer number of privately owned parking lots has provided a non-contentious home for the vast majority of vendors. So while vending has provided economic opportunities across socio-economic, ethnic and native/non-native divides, the wider demographic and spatial context must be recognized. Reaching consensus on which kinds of activity can be tolerated vs. which pose a genuine threat to public order is much more straightforward when the plurality of perspectives, and range and intensity of competing demands on public space, are limited.

Portland's particularities perhaps make an unusual case to generalize from, but several aspects of its street food governance could inform policy elsewhere. For example, while the county's health department recognizes that street vending can pose particular risks, it does not assume a priori that mobile operations are any more dangerous than restaurants. Its health code-unified in 1997, the same year the first pod openedfocuses its licensing criteria on the capacity to mitigate risk rather than necessarily mandating certain kitchen features. A pre-inspection packet (available online) outlines the steps vendors need to take to get started and helps them through a series of didactic question-and-answer sections. Working through these, vendors can ascertain the 
technical standards and practical arrangements required for different tiers of licensure. Food carts in the highest category of licensure can essentially sell anything allowed in a restaurant and vehicles are not required to return daily to a licensed commissary, so long as certain disposal and sanitation conditions are met. Licensing processes also require potential vendors to submit vehicle and equipment details prior to inspection, so the inspector can then help in determining whether any further agency permits or approvals are needed prior to the inspection. The response time once a plan is submitted is generally 10-12 working days and the total cost runs from $\$ 290$ to $\$ 730$, depending on the cart's kitchen capacity.

Portland's planning laws are important too. There is no cap on the number of licenses or vehicles allowed, so long as they meet health department standards. And while the laws on vending in public space are quite restrictive, there are few restrictions related to vending on private property. The city's building codes are written such that if a vending operation is on wheels it is not considered a building. Thus, mobile vendorseven if rarely ever actually mobile-are exempt from regulations faced by restaurants relating to the provision of toilets for customers, disabled access, certain aspects of fire code and service charges for using urban infrastructure. This keeps startup and overhead costs low and gives vendors like Nong tremendous flexibility in how they manage their operations.

At present, the main question about Portland's street food is when will momentum slow? Some local commentators have criticized the trend as overhyped, while competition among vendors has become extremely tight. There have been many business failures in recent years and turnover is high on many of the pods. But so it often goes in the restaurant industry. There have also been some efforts by the Oregon restaurant lobby to press for tighter restrictions because of perceptions that vendors have unfair advantages over traditional restaurants, but to date these have not gone anywhere. To the vendors' benefit, the carts are hugely popular and it would be hard to deny the overall positive effects they have had on the city's social and economic life.

New York vs. Portland?

To summarize conditions in Portland in relation to New York, five points stand out. First, both cities have licensing regimes that are relatively permissive in comparison to many US cities. Vending is a clear part of public culture in Portland and, like New York, the ubiquity of the practice feeds into a social imaginary of the city as a progressive, urbane place where entrepreneurial ambitions can flourish. The social amenities and economic opportunities legal vending provides are widely recognized in both cities. Second, Portland's easier-to-navigate bureaucratic process enables vendors to mitigate health risks by taking much of the guesswork out of regulatory compliance. The emphasis on practical routines and capacities, rather than just material specifications, within application and inspection procedures has helped to develop more of a dialogic relationship among vendors, health officials and enforcement officers in Portland. The regulatory system in Portland has empowered vendors to innovate with new styles and forms of vending that have positively impacted social life and public amenities throughout the city. New York's vendors have followed national trends in street food practices, but not led them.

Third, and in more direct contrast to New York, licensing conditions in Portland have not been used to control the overall numbers of vendors. This matter is understood as falling under the domain of urban planning and economic development, and these departments have restricted vending only according to time, place and manner conditions. Permit caps in New York meanwhile demonstrate how licensing reaches can extend beyond their rationale. Owing to pressures on space in central Manhattan, vending on a citywide basis has been curtailed through health department limits on the number of legally sanctioned vehicles. This arbitrary, illiberal arrangement makes 
it impossible for many licensed vendors to find formal work, generating conditions of illegality, precariousness and wage suppression. It also helps to configure the permit as a kind of 'new property' (Reich, 1964) through which rent can be collected via subcontracting and illegal transfers. The city captures no revenue from this system and incurs a substantial net loss in terms of vendor enforcement owing to the number of fines which are contested or which go unpaid (Davis and Morales, 2012).

Finally, however, and perhaps most significantly, it is important to recognize the tremendous difference in size, density and diversity between the two cities. The intense pressure and competing demands on space in New York, particularly within Manhattan, has few parallels anywhere in the world. Portland is not only substantially smaller with a fraction of the vendor population; it is also one of the least diverse cities in the US and has a great deal of undeveloped land in the urban core. While Portland's vending policies certainly have much to inspire and inform other cities-New York included-the vitality of its vending scene must be considered in light of its relatively non-contentious context. Likewise, given the long, contentious history and fractious politics around vending in New York, the current street-vending policies needs to be viewed more as pragmatic settlement resulting from conflict, struggle and regulatory accumulation rather than the result of a coherently executed political program.

\section{Seattle, Washington: a 'neat and orderly mentality'}

Less than 200 miles north of Portland, Seattle is a much larger and more affluent city. Local press and popular imagination in both cities, however, consider them as rivals. So when Portland started gaining widespread recognition for its street food culture, many of Seattle's foodies began asking why their city was missing out. The numbers were impossible to deny: in 2010, Seattle had roughly 25 vendors selling food on a given day while Portland had over 400 . Seattle had a few celebrated and nationally recognized vendors such as Marination Mobile, but it seemed evident to many that opportunities were being lost. The city's planning department responded with an inquiry and a set of proposed reforms that were adopted in 2011. While it is too soon to draw many firm conclusions on their effects, what Seattle clearly demonstrates is how individual licensing conditions can work in aggregate to highly circumscribe the adoption of new practices, and how licensing laws can prove remarkably durable despite efforts to bring about reform.

- $\quad$ The prohibitive accumulation of licensing conditions

The bureaucratic process that Kamala and Roz had to navigate to get Marination Mobile up and running was far more complicated than that in Portland or New York. Recall, both women had high-level managerial experience and a substantial sum of money to invest. Kamala described getting licensed and satisfying various departmental criteria as 'a full time job for six weeks'. Even after they had found a truck, developed a business concept and plan, they still had to meet licensing requirements that included a business license ( $\$ 15)$ and trade name filed ( $\$ 5)$; a vehicle plan review ( $\$ 764)$; a separate inspection for vehicles manufactured outside of the state (\$400-1,000); a health license (\$332-768 depending on risk tier category); a food workers exam (\$10); a fire safety permit ( $\$ 440$, plus temporary events); a street use permit ( $\$ 146$ base fee, plus $\$ 121$ monthly in summer); a licensed commissary agreement and inspection (\$229); and insurance coverage of $\$ 1$ million with the City of Seattle named as an additional insured.

Their total administrative and licensing fees came to roughly $\$ 5,000$. In New York, the cost is less than $\$ 300$ and in Portland it ranges from $\$ 290$ to $\$ 730$. While this is enough to put most aspiring vendors off, three additional licensing barriers are crucial. First, the health department requires proof of permission to use a toilet within $200 \mathrm{ft}$ ( $61 \mathrm{~m}$ ) of every vending location. The city has few public toilets, so written permission to use a private one often comes at a price (as much as $\$ 300$ near the 
downtown sports stadiums, for example). The stipulation also curtails vending outside of normal business hours and in neighbourhoods where few businesses are located. Second, until 2011 vendors needed written approval to locate adjacent to an existing business-a stipulation that effectively allowed property owners to regulate the public realm beyond their property lines. Third, the city had extraordinarily tight restrictions on which foods vendors could sell. City rules (not those of the health department) specifically limited the sale of street food to popcorn, nuts, seeds, coffee and hotdogs. Each of these restrictions dated back to the early 1980s when vending was curtailed as part of efforts to correct 'downtown blight' and aesthetically align downtown streets and sidewalks with the 'neat and orderly mentality' of the local citizenry (Seattle DPD, 2011).

Seattle's laws against vending stood largely unchallenged for over three decades, illustrating how reactionary pressure to create strict licensing conditions can eradicate a practice rather than manage it. That hotdogs-a notoriously unhealthy food-came to be the one menu item that was sure to pass health inspections in Seattle (and New York) clearly indicates some inconsistent and culturally narrow logics. Once enshrined in licensing conditions, however, these details can be difficult to change. They form the basis for practical and institutional norms that limit perceptions of what else might be possible. Kamala and Roz were part of a small group that creatively and determinedly waded through the barriers and high costs in Seattle. Their food is highly regarded, but their success has been aided by being one of relatively few vendors in the city as the craze for innovative street food became a national trend.

- $\quad$ The durability of licensing conditions and the difficulties of reform

Officials in Seattle spent three years discussing how to improve opportunities for street food vending in their city. The Department of Planning and Development (DPD) led these efforts, largely in hopes that vendors might bring economic vitality and street life to the city's relatively underused and somewhat sterile downtown. While vendor licensing in Seattle falls largely under the jurisdiction of the county's health department, the DPD had at their disposal a number of regulations that could be removed or reformed to encourage the practice. The obvious place to begin was repealing the municipal code that narrowly listed specific foods that could be sold. This was followed by a proposal to scrap the rule giving property owners final say on vendors locating near them. The rest of the DPD proposals related mostly to decreasing required setbacks from curbs, building entrances, schools, restaurants and other features that made vending legally impossible in many public spaces of the city. Perhaps most novel, the DPD's proposal made provisions to allow 'food vending zones' to be established through street-use permitting so that trucks, in some cases, could pay a fee to use public parking spaces.

Public hearings on the bill predictably sparked discontent among some restaurant and property owners who were against any relaxing of vending conditions. However, the DPD had anticipated resistance and granted a number of concessions in advance. Their proposals stipulated that vendors would be required to have a $50 \mathrm{ft}(15 \mathrm{~m})$ setback from any food-service business and vendors would be limited to two per block face regardless of density. The various licensing criteria also remained spread out across multiple departments, with aggregate fees remaining in the range of $\$ 2,500-4,500$. Recall that fees in New York and Portland are less than $\$ 300$ and $\$ 730$ respectively. The most restrictive conditions, however, remain those specified by the county's public health department. The persistence of the $200 \mathrm{ft}(61 \mathrm{~m})$ bathroom rule excludes many potential vending spaces, while food preparation requirements require daily mobility and impose several practical burdens. Even fully equipped trucks are not allowed to have food prepared on them, nor can they cook anything thicker than one inch $(2.54 \mathrm{~cm})$. The requirement for vehicles to return daily to a commissary prevents the development of 
stationary style vending which is popular in Portland. Yet should the health department decide that a properly sanitary cart is possible without the use of a commissary, the city's land-use laws would require them to meet a range of building standards and fees, including on-board toilets, which are simply unfeasible on most carts or trucks.

While officials from departments of health and land use were involved in discussions of Seattle's legislative proposals, there was no talk at the hearings of reevaluating the regulations falling under their jurisdiction. The county health board was sent a resolution by the council asking them to support the city's initiative, but details on what this might mean were unclear and never part of formal policy. Nor were questions raised in hearings about which health or land-use guidelines might be excessive, outdated or amendable. A few city employees speculated off record that this was because raising such discussions would require bringing county- and state-level policymakers to the table. The trope of 'death by committee' was evoked to describe the likelihood of the bill stalling completely if debate went on too long or involved too many actors. This does not suggest that Seattle officials have a problem with democratic or bureaucratic procedure necessarily. Rather, and as we have seen within New York's licensing laws, it indicates how different scales of government are often held apart through the 'machinery of jurisdiction' (Valverde, 2009b) which is rarely coordinated or harmonized in the governance of cities. The more general point to be made here is that while licensing can help to disperse responsibility for management and oversight, restrictive conditions can accumulate in both space (e.g. across different departments) and time (through different modes of prevention and punishment) to make reordering public life a highly uncertain project.

Seattle's new street food bill was passed unanimously in 2011 with only very modest changes to the original proposal. Its passage was treated as a celebratory occasion, taking place among a circle of vendors specially assembled for the mayor's signing. Kamala, who had argued in favour of the bill at public hearings, was invited to speak at the ceremony and Marination Mobile was praised by the mayor as being at the vanguard of a change in the city's street food offerings. However, Kamala admittedlike most of the vendors I spoke with-that the new legislation is unlikely to affect her business because regulatory conditions still narrowly restrict the kinds of foods that can be prepared and make it much more preferable to be located on private property.

\section{- $\quad$ Seattle vs. New York and Portland?}

Juxtaposing Seattle with Portland and New York further demonstrates how licensing laws configure relations between order and opportunity in the collective life of a city. Importantly, this is an ambiguous relation and not a zero-sum game. We have seen, for example, that the city whose regulatory system makes licenses and municipally owned spaces most readily accessible to vendors-New York-also has the greatest amount conflict over the practice. Yet the laws which protect the ability of New Yorkers to use their streets and sidewalks to vend-that is, to privatize them temporarily for the sake of profit-is a certain kind of right to the city that does not exist in most cities. While the current system produces inequalities and hardships, it has also enabled an active public of vendors and their supporters to form and subsequently make demands for more equitable and just conditions. Conversely, Seattle's relatively prohibitive policies and proscriptive form of ordering have inhibited the trade historically and continue to exclude those who could likely benefit from it most. Connecting to a wider public discourse about Seattle and especially its downtown being exclusively geared in favour of the affluent ( $c f$. Beckett and Herbert, 2009), the collective result is a diminished set of possibilities that the city's public life affords. Portland's laws governing the use of public spaces are similarly restrictive to Seattle, yet they coexist with fairly relaxed rules about open private spaces. While the city's abundance of private lots is a key factor, 
like New York, the everyday experience of street food related activity nonetheless feeds into the 'symbolic projection' (Amin, 2008) of the city as a place that supports the needs and desires of a wide variety of its inhabitants.

Three years following Seattle's regulatory reforms, there are signs that a new culture of street food has begun to develop. Although nothing like New York or Portland, more than 80 carts and trucks now operate in Seattle on a given day and there are lots of temporary events and festivals throughout the year. Most of the vendors do not work downtown as the DPD hoped to encourage, but rather outside the corporate offices of companies like Starbucks and Microsoft and on private lots in the more affluent neighbourhoods. However, a number of Portland-style pods have also started to appear around the city. Adapting the idea to Seattle's licensing and planning rules, parking lot owners rent spaces on a daily basis to multiple vendors who then return their vehicle to a commissary at night. The arrangement presents something of a compromise between the concerns of some city officials and business owners; the spatial needs of vendors; and the popular demand for this new form of public amenity. Finally, while the current trendiness of street food comes with certain ambivalences (Zukin, 2009; Dunn, 2014a), recent developments in Seattle, New York and Portland give reasons to be hopeful that more mutually beneficial ways of ordering urban space might be gained in other cities too (Koch, 2011).

\section{Conclusion: assembling the spaces of public life}

As transformations to conventional forms of public life unfold, urban research can play a vital role in helping to interpret them. Emerging landscapes, however, should be viewed as more than simply texts through which to read larger processes or as a canvas upon which to project our criticisms. If our aim is to help realize the potential of the city as a common good, we must be more attuned to auditing and evaluating how particular configurations of public life are assembled. There is much work to be done on this front and as critical scholars there is much that we can offer. But our notion of what counts as properly political must extend into arenas often thought to be too mundane to warrant our attention. We must become more adept at engaging with practical problems and looking for insights that can enable us to talk to policymakers, bureaucrats and a range of urban practitioners. Suspicions that reformist politics can foreclose more radical possibilities are not unfounded, but they can also limit our ability to make meaningful contributions to the making of better cities.

This inquiry into the operations and effects of licensing has highlighted a technique of government ubiquitous to how public spaces and popular practices are managed. In doing so, it reiterates Amin's (2008: 14) claim that 'the rules and routines of ordering' are not the nemesis of public life but are essential to the making of it. Licenses are key means of distinguishing what sorts of activities and objects are deemed appropriate in the shared spaces of the city. They are also a primary technique for monitoring the risks they entail and delegating responsibility for them. Importantly, licensing laws work not only on behalf of established interests, property owners and profit seekers; they can also enable public bodies to make demands on such groups in the service of a greater public good (Valverde, 2009a).

Balancing concerns for order and safety with personal and collective freedoms is an ongoing project animated by the multiplicity of difference and possibility in how societies are governed. A key promise of assemblage approaches to urban research is they can 'open up black-boxed arrangements and ways in which actors, things, or processes are made present and made absent' (Farías, 2011: 733). Curiously, licensing is a legal technology that operates precisely through a certain kind of black boxing that renders it largely invisible in its own success (Latour, 1999). Conflict and disorder in the public realm are minimized through a dispersed form of state power in which the 
need for state officials to be consistently present is also minimized. Given the many more obvious forms of discipline and surveillance that go on in cities, it is perhaps understandable that licensing regimes have largely escaped critical academic scrutiny.

By way of concluding, a first and perhaps obvious point is that a whole range of licensing regimes has yet to be analysed in terms of the relations of power in which they are embedded and the effects which they produce. Research in this vein can start by clarifying different licensing conditions and processes, unpacking their institutional arrangements and origins, and questioning what or whose interests are served by them. Insights from areas such as critical legal studies and sociology of law might be drawn more closely into urban studies to investigate how determinations of order and disorder are made, and how social factors including income, race, nativity and gender mediate how licensing is operationalized in policymaking and enforcement routines. Questions can then be asked about the appropriateness of different licensing systems, how they have evolved in response to conflicts or changing circumstances, and the extent to which they might be politicized and changed through bureaucratic process or democratic decision-making.

Critical inquiries into licensing might be further developed in response to calls for new forms of comparative urban scholarship (McFarlane, 2010; Robinson, 2011). Examining government and law across different urban contexts can be complicated (Pierre, 2005; Philippopoulos-Mihalopoulos, 2007) but this study has shown that licensing provides a coherent 'unit of analysis' (Robinson, 2011) for investigating how different socio-legal arrangements configure order and opportunity in different ways. Crucially, focusing on how particular problems arise and are managed leads to practical insights that do not necessarily arise when comparisons begin with a concept or theory. Such insights can be used to develop understandings about different forms of 'good practice' but also to consider what can go wrong when planners seek to intervene in complex systems (Roy, 2005). Incorporating the experiences of different municipalities and jurisdictions as they attempt to deal with issues such as informality, nuisance and risk, revenue shortages and enforcement challenges can offer crucial insights about the merits of possible regulatory changes-including those ranging from small administrative tweaks to more wholesale licensing reform-and about the mechanics of urban governance more generally. Importantly, because licensing laws often serve to depoliticize contentious issues, it is precisely through practices of comparison that inequalities and missed opportunities can be brought to the fore.

Finally, examining the operations and effects of licensure can help to extend understandings of power and influence that do not fall into neat hierarchies or institutional scales (Valverde, 2009b). By drawing everyday practices and objects more centrally into studies of urban governance, a focus on licensing emphasizes how municipal regulatory regimes are about much more than abstract political rationalities being implemented in a top-down fashion. ${ }^{9}$ Prevailing urban orders are composed of heterogeneous elements-knowledge practices, material forms, institutional structures and technologies of power-configured through, and in response to, the challenges and contingencies of living together in diverse societies. Licensing offers just one of many techniques and interfaces through which governments attempt to manage such relations, but their effects often fail or exceed their intended rationale. As with tools like permits, land-use restrictions and zoning, they need to be understood as more than a matter of routine bureaucracy or as something to which only planners or policymakers might attend (Valverde, 2003; 2012). A more attentive focus on how different legal

9 The licensing of alcohol, for example, demonstrates how licensing conditions have shaped domestic consumption patterns, national-level data collection processes, regional drinking cultures, transnational networks of alcohol distribution, and international discourse on public health and other related topics (cf. Valverde, 2003; Latham, 2011; Beckingham, 2012). Such effects are often (but certainly not always) unimagined or inconceivable at the point of local regulatory decision-making processes, but they are revealing of the topological landscapes through which governance is constructed. 
techniques are enrolled into projects of governing, and how they help to assemble different spaces of public life, can provide urban scholarship with a productive pathway for further urban research and greater leverage in bringing forth better ways of organizing our cities.

\section{Regan Koch, School of Geography, Queen Mary University of London, Mile End Road, London E1 4NS, UK, r.koch@qmul.ac.uk}

\section{References}

Amin, A. (2008) Collective culture and urban public space. City 12.1, 5-24.

AMNY (amNewYork) (2011) Street-vendor group supports letter-grade system for food trucks. A.M. New York. [WWW document]. URL http://www.amny.com/ urbanite-1.812039/street-vendor-group-supportsletter-grade-system-for-food-trucks-1.3349963 (accessed 29 November 2011).

Baldwin, P. (1999) Domesticating the street: the reform of public space in Hartford, 1850-1930. Ohio State University Press, Columbus, $\mathrm{OH}$.

Barnett, C. (2014) How to think about public space. In P. Cloke, P. Crang and M. Goodwin (eds.), Introducing human geographies, third edition, Routledge, London.

Beckett, K. and S. Herbert (2009) Banished: the new social control in urban America. Oxford University Press, New York, NY.

Beckingham, D. (2012) Gender, space, and drunkenness: Liverpool's licensed premises, 1860-1914. Annals of the Association of American Geographers 102.3, 647-66.

Blomley, N. (2010) Rights of passage: sidewalks and the regulation of public flow. Routledge, New York, NY.

Bluestone, D. (1991) The pushcart evil: peddlers, merchants, and New York City's streets, 1880-1940. Journal of Urban History 18.1, 68-92.

Browne, G., W. Dominie and K. Mayerson, (2014) 'Keep your wheels on': mediating informality in the food cart industry. In V. Mukhija and A. Loukaitou-Sideris (eds.), The informal American city: beyond taco trucks and day laborers, MIT Press, Cambridge, MA.

Chastain, A. (2010) Food carts as retail real estate. Quarterly \& Urban Development Journal 2 (May), 61-70.

Coulmont, B. and P. Hubbard (2010) Consuming sex: sociolegal shifts in the space and place of sex shops. Journal of Law and Society 37.1, 189-209.

Crawford, M. (1999) Everyday urbanism. In J. Chase, M. Crawford and J. Kaliski (eds.), Everyday urbanism, Monacelli Press, New York, NY.

Davidson, A. (2013) The food-truck business stinks. The New York Times [WWW document]. URL http://www. nytimes.com/2013/05/12/magazine/the-food-truckbusiness-stinks.html?pagewanted=all\&_r=0 (accessed 6 June 2013).

Davis, J. and A. Morales (2012) Fining the hand that feeds you: street vendor fines and increasing revenues to New York City. Working paper, Department of Urban and Regional Planning, University of WisconsinMadison [WWW document]. URL http://papers.ssrn. com/sol3/papers.cfm?abstract_id $=2122594$ (accessed 7 June 2012).

Devlin, R. (2010) Informal urbanism: legal ambiguity, uncertainty, and the management of street vending in New York City. PhD thesis, Department of City and Regional Planning, University of California, Berkeley.

Devlin, R. (2011) An area that governs itself: informality, uncertainty and the management of street vending in New York City. Planning Theory 10.1, 53-65.

DOI (2009) DOI undercover operation exposes illegal, black market in mobile food vending permits and results in the arrest of six individuals. Press Release 61-2009, City of New York Department of Investigation, New York, NY.

Dunier, M. (1999) Sidewalk. Straus and Giroux, New York, NY.
Dunn, K. (2014a) Street vendors in and against the global city: VAMOS Unidos. In R. Milkman and E. Ott (eds.), New labor in New York: precarious worker organizing and the future of unionism, Cornell University Press, Ithaca, NY.

Dunn, K. (2014b) Flexible families: Latina/o food vending in Brooklyn, New York. In K. Graff and N. Ha (eds.), Urban street vending in the neoliberal city: a global perspective on the practices and policies of a marginalized economy, Berghahn Books, Oxford.

Edge, J.T. (2012) The truck food cookbook: 150 recipes and ramblings from America's best restaurants on wheels. Workman Publishing Company, New York, NY.

Farías, I. (2009) Introduction: decentring the object of urban studies. In I. Farías and T. Bender (eds.), Urban assemblages: how actor-network theory changes urban studies, Routledge, New York.

Farías, I. (2011) The politics of urban assemblages. City 15.3/4, 365-74.

Flyvbjerg, B. (2006) Five misunderstandings about casestudy research. Qualitative Research 12.2, 219-45.

Gottlieb, J. (2009) Taco trucks are feeling the crunch across the U.S. Los Angeles Times [WWW document]. URL http://articles.latimes.com/2009/may/20/local/metacotrucks20 (accessed 12 October 2015).

Greenberg, M. (2008) Branding New York: how a city in crisis was sold to the world. Routledge, New York, NY.

Hall, S. (2012) City, street and citizen: the measure of the ordinary. Routledge, London.

Hammond, B. (2009) In a changing world Portland remains overwhelmingly white. Portland Oregonian [WWW document]. URL http://www.oregonlive.com/news/ index.ssf/2009/01.html (accessed 10 September 2012).

Handley, A. (2009) Tweetable eats: what street vendors can teach businesses about Twitter. Mashable Business [WWW document]. URL http://www.mashable. com/2009/07/17/twitter-street-vendors/(accessed 15 July 2011).

Hannah-Jones, N. (2011) In Portland's heart, 2010 census shows diversity dwindling. Oregon Live [WWW document]. URL http://www.fhco.org/pdfs/news/ NEWS_PDXDiversityDwindling 04302011.pdf (accessed 10 May 2012).

Harvey, D. (1989) From managerialism to entrepreneurialism: the transformation in urban governance in late capitalism. Human Geography 71.1, 3-17.

Hernandez-Lopez, E. (2010) LA's taco truck war: how law cooks food culture contests. Chapman University Law Research Paper [WWW document]. URL http://works. bepress.com/ernesto_hernandez/10 (accessed 21 July 2012).

Heying, C. (2010) Portland's artisan economy: the arts and crafts sector. Ooligan, Portland, OR.

Hubbard, P., R. Matthews and J. Scoular (2009) Legal geographies-controlling sexually oriented businesses: law, licensing, and the geographies of a controversial land use. Urban Geography 30.2, 185-205.

Holston, J. (2008) Insurgent citizenship: disjunctions of democracy and modernity in Brazil. Princeton University Press, Princeton, NJ.

Jacobs, J. (1961) The life and death of great American cities Random House, New York, NY.

Johnston, J. and S. Baumann (2010) Foodies: democracy and distinction in the gourmet foodscape. Routledge, New York, NY. 
Kleiner, M. and A. Krueger (2010) The prevalence and effects of occupational licensing. British Journal of Industrial Relations 48.4, 676-87.

Koch, R. (2011) Food: the 'new art' of the urban experience? In M. Chang and L. Meusberger (eds.), The food junctions cookbook: living recipes for social innovation, UCL Office of Public Engagement, London.

Koch, R. and A. Latham (2012) Rethinking urban public space: accounts from a junction in West London. Transactions of the Institute of British Geographers $37.4,515-29$

Koch, R. and A. Latham (2013) Inhabiting cities, domesticating public space: making sense of the changing public life of contemporary London. In A. Madanipour, S. Knierbein and A. Degros (eds.), Public space and the challenges of urban transformation in Europe, Routledge, London.

Latham, A. (2011) Topologies and the multiplicities of space-time. Dialogues in Human Geography 1.3, 312-15.

Latour, B. (1999) Pandora's hope: essays on the reality of science studies. Harvard University Press, Cambridge, MA.

Loukaitou-Sideris, A. and R. Ehrenfeucht (2009) Sidewalks: conflict and negotiation over public space. MIT Press, Cambridge, MA.

Low, S. and N. Smith (2006) The politics of public space. Routledge, New York, NY.

McFarlane, C. (2010) The comparative city: knowledge, learning, urbanism. International Journal of Urban and Regional Research 34.4, 725-42.

Mesh, A. (2010) Cartpocalypse! Willamette Weekly [WWW document]. URL http://www.wweek.com/portland/ article-16493-cartpocalypse_.html (accessed 5 October 2012).

Mintzer, R. (2011) Start your own food truck business. Entrepreneur Press, Irvine, CA.

Morrow, J. (2009) Red tape helps push food carts off the street. Toronto Star [WWW document]. URL http://www. thestar.com/news/gta/2009/08/28/red_tape_helps_ push_food_cart_off_street.html (accessed 5 May 2012).

Mukhija, V. and A. Loukaitou-Sideris (2014) The informal American city: beyond taco trucks and day laborers. MIT Press, Cambridge, MA.

Parsa, H., J. Self, D. Njite and T. King (2005) Why restaurants fail. Cornell Hotel and Restaurant Administration Quarterly 46.3, 304-22.

Philippopoulos-Mihalopoulos, A. (ed.) (2007) Law and the city. Routledge, Oxon

Pierre, J. (2005) Comparative urban governance: uncovering complex causalities. Urban Affairs Review $40.4,446-62$

Pilcher, J.M. (2008) Who chased out the 'Chili Queens'? Gender, race, and urban reform in San Antonio, Texas, 1880-1943. Food and Foodways 16.3, 173-200.

PSU (2009) Food cartology: rethinking urban spaces as people spaces. Department of Urban Planning, Portland State University, Portland, OR [WWW document]. URL https://www.portlandoregon.gov/bps/ article/200738 (accessed 20 October 2015).

Reddy, S. (2011) Prices for food-cart permits skyrocket. The Wall Street Journal [WWW document]. URL http://
online.wsj.com/article/SB10001424052748704758904 576188523780657688.html (accessed 4 April 2012).

Reich, C. (1964) The new property. Yale Law Journal 73.5, 733-87.

Roberts, S. (2013) The six-figure price tag for selling a $\$ 2$ hot dog. The New York Times [WWW document]. URL http://www.nytimes.com/2013/09/05/nyregion/thesix-figure-price-tag-for-selling-a-two-dollar-hot-dog. html?pagewanted=all\&_r=0 (accessed 4 August 2014).

Robinson, J. (2011) Cities in a world of cities: the comparative gesture. International Journal of Urban and Regional Research 35.1, 1-23.

Rodgers, K. and K. Roy (2010) Cartopia: Portland's food cart revolution. Roy Rodgers Press, Portland, OR.

Roy, A. (2005) Urban informality: toward an epistemology of planning. Journal of the American Planning Association 71.2, 147-8.

Sayer, A. (2011) Why things matter to people: social science, values and ethical life. Cambridge University Press, Cambridge.

Seattle DPD (2011) Seattle street food initiative. Seattle Department of Planning and Development [WWW document]. URL http:// www.seattle.gov/transportation/docs/stuse/ SeattleStreetFoodInitiativeDirectorReportFeb162011. pdf (accessed 4 December 2011)

Shouse, H. (2011) Food trucks: stories and recipes from America's best kitchens on wheels. Ten Speed Press, Berkeley, CA.

Skolnick, J. and J. Dombrink (1978) The legalization of deviance. Criminology 16.2, 193-208.

Smith, N. (1996) The new urban frontier: gentrification and the revanchist city. Routledge, New York, NY.

Stoller, P. (2002) Money has no smell: the Africanization of New York City. University of Chicago Press, Chicago, IL.

Vallianatos, M. (2014) A more delicious city: how to legalize street food. In V. Mukhija and A. Loukaitou-Sideris (eds.), The informal American city: beyond taco trucks and day laborers, MIT Press, Cambridge, MA.

Valverde, M. (2003) Law's dream of a common knowledge. Princeton University Press, Princeton, NJ.

Valverde, M. (2009a) Laws of the street. City \& Society 21.2, 163-81.

Valverde, M. (2009b) Jurisdiction and scale: legal 'technicalities' as resources for theory. Social \& Legal Studies 18.2, 139-57.

Valverde, M. (2011) Seeing like a city: the dialectic of modern and premodern ways of seeing in urban governance. Law \& Society Review 45.2, 277-312.

Valverde, M. (2012) Everyday law on the street: city governance in an age of diversity. University of Chicago Press, Chicago, IL.

Vaz, P. and Bruno, F. (2003) Types of self-surveillance: from abnormality to individuals 'at risk'. Surveillance \& Society 1.3, 272-91.

Wood, D. (2003) Foucault and panopticism revisited. Surveillance \& Society 1.3, 234-39.

Zukin, S. (2009) Naked city: the death and life of authentic urban places. Oxford University Press, New York, NY and Oxford. 